\title{
Manifiesto de transdisciplinariedad Para no volvernos esclavos del conocimiento de otros
}

\author{
Por Lewis R. Gordon
}

$\mathrm{E}$ sta Universidad fue fundada como un instituto de negocios*.La sabiduría de su administración ha consistido en saber que no se puede vivir únicamente de los negocios. Así, al expandir el conocimiento, ha tenido en cuenta que los estudiantes necesitan de la educación para no volverse esclavos del conocimiento de otros.

La mayor parte de mi trabajo tiene que ver con revelar cosas que están en nuestro alrededor pero que nosotros, a menudo, no notamos. Parece raro, pero en ocasiones las cosas más obvias son las más invisibles.Y esta es la razón por la cual me dedico a este trabajo, a cosas que necesitamos ver a través del tiempo. Esto hace que mi labor se perciba como algo muy novedoso; pero espero que, mientras hablo con ustedes, les parezca familiar.

Existen muchos temas que pueden ser tratados en esta conferencia.Por esta razón voy a hablar únicamente de algunos. Mi trabajo se ha centrado en estudiar tres cuestiones. Primero, la pregunta de la antropología filosófica, que es la interrogante sobre ¿quiénes somos? Segundo, la pregunta acerca de la libertad, la cual puede expresarse así: ¿qué queremos llegar a ser? Y la tercera, que es muy técnica, la metacrítica de la razón, que tiene que ver con cómo justificar la forma en que hablamos sobre ¿qué debemos ser? y ¿qué queremos ser?. Estas preguntas son importantes tanto para una institución que tiene la responsabilidad de pensar en cómo convertirse en una Universidad que no es simplemente un clon de otras, una imitación de las demás, como también para las ciencias sociales y las humanidades. En esta oportunidad me centraré en la tercera cuestión: en cómo hablar de ¿qué debemos ser? y ¿qué queremos ser?, porque estas dos preguntas van juntas.

En el centro de mi discurso está la razón como problema. Cuando escuchamos hablar sobre la razón pensamos, a menudo, que razón y racionalidad son la mis-

*Discurso pronunciado en la Universidad Icesi de Cali, en el Tercer Congreso Colombiano de Filosofía, Cali, 21 de octubre de 2010. Nota del editor: el autor se refiere específicamente a la Universidad Icesi,lugar donde realizó esta conferencia. La cual fue traducida del inglés al español por José Miguel Terán, David Ricardo Luna, Ricardo Adolfo Coutin, vladimir Rouvinski y Rafael Silva Vega, miembros del Comité Editorial de esta publicación. 
ma cosa. Pero la racionalidad requiere ser consistente. Entonces, si uno debe ser consistente hasta el final, debe ser consistente con esa consistencia, lo que hace que la racionalidad lleve a una hiperconsistencia.¿Pueden imaginarse ustedes una cita con una persona consistente al máximo? ¿Les gustaría vivir con una persona hiper- racional? Ustedes pueden notar el problema de inmediato: si eres demasiado racional, eres irracional.Y esto nos dice que la razón es más amplia que la racionalidad. Esta conflictiva relación entre la razón y la racionalidad afecta gran parte del pensamiento moderno.

Una buena parte del pensamiento moderno trata de encadenar la razón, de sustituir a la razón por la racionalidad. Pero el problema es que, así,vamos a parar a la irrazonabilidad.Desde esta perspectiva, el conflicto consiste en qué hacer con esta tensión. Hay otras formas en las que esto se manifiesta.Por ejemplo,yo estudié filosofía,y cuando estaba en la escuela de postgrado, caí en cuenta de que varios de los grandes filósofos no apreciaban a las personas negras.Varios de mis profesores no estaban dispuestos a aceptarlo y tuve que mostrarles pasajes precisos de los textos donde esto se evidenciaba.Después, pensé que cuando se estudia a los grandes filósofos nos encontramos con personas que se obsesionan con cada una de sus palabras. Entonces, me pregunté: ¿por qué abandonan a los grandes filósofos, de repente, cuando se trata de racismo? Yo llamo a eso la teodicea del texto.La teodicea se refiere a como uno se relaciona a la benevolencia de Dios. Uno se cuestiona,si Dios es todo poderoso, entonces, ¿es Dios el responsable del mal? Las dos respuestas clásicas a la teodicea son: primero, decir que somos limitados y que no entendemos el fin último de Dios; segundo, afirmar que Dios nos dio el libre albedrío, que nosotros podemos cometer el mal, pero Dios no es el responsable.En efecto,esto quiere decir que algo anda mal con los seres humanos. Ahora,cuando algunos de mis profesores trataron de decirme que el error no estaba en los textos sino en la forma como los interpretamos, o en alguna otra cosa, ellos estaban tratando al autor del texto como a Dios. Por ello esto puede ser considerado como teodicea.

Entonces, la cuestión es: ¿por qué yo veo estas cosas y ellos no? Esto se debe a la teodicea. Cuando uno lee a un autor como si fuese Dios, uno se olvida que los seres humanos son imperfectos.Los libros son escritos por hombres, éstos cometen errores,y nuestra tarea,como pensadores activos, es entender estos errores y mejorar el conocimiento. El error que mis colegas cometieron, fue el de creer que yo buscaba rechazar esos textos dado su contenido racista. Ellos pensaban que yo estaba diciendo que no los leyeran. Al igual que en la teodicea, Dios crea el mal pero no es responsable de él. Pero lo que yo expresaba,desde mi posición como una persona negra y como alguien que creció en un mundo que no quería a las personas negras, es que yo necesitaba aprender a entender y respetar a los otros seres humanos, aun con sus odios. Entonces yo no esperaba leer a dioses. Yo esperaba leer a los hombres.

Ahora, esto hace parte de aquello a lo que me estoy refiriendo hoy. Dado que las ciencias que tenemos son hechas por hombres, algunos críticos se preguntarán por qué mi respuesta no fue la de deshacerme de la filosofía. Yo no soy un 
filósofo nacionalista.Y, a medida que voy hablando, ustedes comprenderán que estoy comprometido en entender cómo se encuentran las disciplinas.A este respecto, creo que el interrogante primordial para todos los que están comprometidos con la vida del pensamiento es: ¿por qué pensamos? Alrededor suyo hay un mundo de violencia pobreza, disparidad.Pero usted se pregunta: ¿por qué piensa?

Cuando algunas personas se dan cuenta de que yo también soy filósofo - yo no soy únicamente filósofo, también hago sociología - me dicen que prefieren lo práctico a lo teórico.Algunas personas dicen que ellos prefieren la experiencia.Pero hay un problema con esto: todos ustedes en este recinto tuvieron una experiencia al tratar de comprender su experiencia. Ustedes han vivido la experiencia de que algo les ha sucedido, pero no pueden imaginarse qué fue y lo que ustedes quieren hacer de inmediato es ir y hablar con alguien, un amigo, por ejemplo.Ustedes lo que están tratando de hacer es entender $s u$ experiencia.Y lo que ustedes, en este caso, están haciendo es apelar a la teoría para darle un significado a su experiencia.Sin embargo, si usted confía en alguien para que le diga en qué consiste su experiencia, entonces usted se vuelve dependiente de la interpretación de su experiencia, de que ese alguien le cuente qué es lo adecuado para su vida. Yo le llamo a esto una colonización epistemológica.

Hay otro tipo de colonización epistemológica. Es una colonización al nivel de los métodos. Se trata no solamente de la colonización de qué es lo que usted piensa, sino, también, de cómo usted piensa. Entonces, nosotros encontramos estas prácticas vivas en los escenarios de lo que yo llamo la decadencia disciplinaria. Es en este momento cuando la disciplina se aleja de lo que le da vida. Este es el significado de "decaer", "morir". Una forma de esta decadencia es la fetichización metodológica: métodos fetichizantes.Es en este instante cuando un académico o un estudiante puede analizar algo, trabajar duro en eso y difundirlo en la comunidad, mientras que otros están interesados sólo en los métodos. Estos últimos no están interesados en si esto es verdad o real.

El otro término es solipsismo disciplinario. Esto es cuando creemos que una disciplina cubre toda la realidad.Ejemplos de esto se dan cuando un sociólogo critica al historiador por no ser sociológico; cuando un teórico literario critica a un sociólogo por no ser un crítico literario; o cuando un científico natural aparece y dice: "lo que tú haces no es ciencia”.

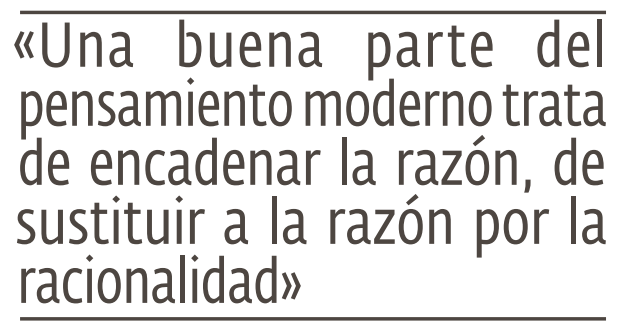

Entonces ¿qué está pasando? Bueno, hablemos de los seres humanos. El filósofo y sociólogo afroamericano W.E.B.Du Bois evidencia un problema cuando la gente de color es estudiada desde varias disciplinas. Ellos terminan convirtiendo a la gente en el problema, en vez de estudiar el problema que la gente enfrenta.Cuando sus métodos no se adecuan a la vida de las personas, dicen: ¿qué es lo que está mal en estas personas? Pero nunca se preguntan que está mal con sus métodos. La falacia de los métodos del trabajo divino es que 
suponen que el método en sí ya abarca toda la realidad. Pero los métodos son productos de los seres humanos, $y$, hasta donde yo sé, ningún ser humano podría abarcar toda la realidad. Esto puede ser llamado la colonización de los métodos.A este respecto, existe un autor que aboga por una des-colonización.Me refiero a Nelson Maldonado-Torres.Este autor argumenta a favor del pensamiento des-colonizado. Tengo una palabra técnica fea,o,más bien, varias palabras para describir el pensamiento des-colonizado. Para responder a la decadencia disciplinaria se requiere una suspensión teleológica de la disciplinariedad.Lo que esto significa es estar dispuesto a ir más allá de su disciplina por el bien de la realidad.Si la gente no puede ser explicada por la teoría o disciplina, es necesario cambiar la teoría,la disciplina, el método.

Algunas personas de las ciencias sociales y las humanidades piensan que cuando yo digo esto me refiero a la interdisciplinariedad, pero el problema con

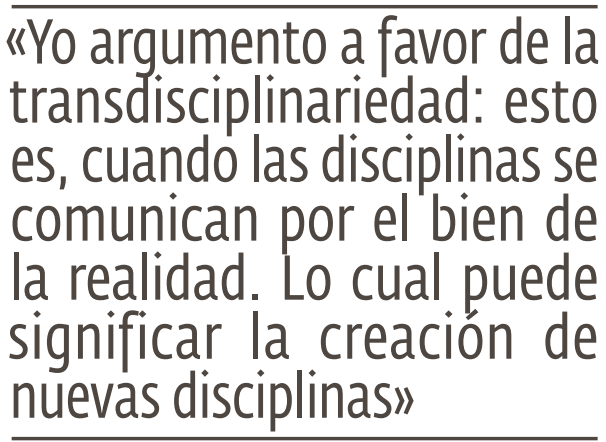

la interdisciplinariedad es que cada una de las disciplinas se considera en sí misma como autosuficiente. Sin embargo,yo hace poco afirme que esto es inexacto. $\mathrm{Si}$ son autosuficientes, no tienen por qué comunicarse, ya que cada una puede dar respuestas a toda la realidad.Entonces, yo argumento a favor de la transdisciplinariedad, esto es, cuando las disciplinas se comunican por el bien de la realidad. Lo cual puede significar la creación de nuevas disciplinas. Muchos de nosotros nos olvidamos de que las disciplinas que hemos estudiado no existían antes: nosotros las creamos y depende de nosotros tener la responsabilidad de los conocimientos que ellas producen.

Dos temas sobre la transdisciplinariedad nos llevan de vuelta a mis comentarios iniciales. Uno de estos es la realidad social.En la actualidad,en muchos países, la gente efectivamente hace sociología, pero no están interesados en el trabajo social. Esto es muy extraño. Del mismo modo, las ciencias humanas tienen el problema de la realidad humana: ¿por qué la realidad social es importante? La realidad social reúne a la comunicación, la intersubjetividad y la colaboración, lo que significa compartir un mundo, en el que usted puede incluso tener pruebas para evaluar la ciencia. Pero la palabra colaboración proviene de la palabra latina collabōrāre y significa caer juntos. Luego,lo que lo que quiero decir con esta palabra es que nosotros dependemos unos de otros para construir el conocimiento, pero, si fallamos, nos caemos todos. La cuestión de la realidad humana se vuelve aún más complicada porque los seres humanos están siempre más allá de las normas que nosotros les establecemos. Si yo le dijera a cada uno de ustedes qué hacer, ustedes me mirarían y harían otra cosa.Y esto es así porque el mundo humano está gobernado por la libertad. Pero el mundo de los humanos es, también, creado por los seres humanos, por el bien de ellos 
mismos. Sigmund Freud lo expresó así: la palabra humana crea un dios que les ayuda, y este dios es la cultura.

Ahora, ¿qué hacemos con la cultura? Una cosa es cómo se ocupa el ser humano de la naturaleza. El universo es más grande que cualquiera de nosotros. La segunda cosa es nuestros cuerpos. Muchos de ustedes son vibrantes y jóvenes ahora, pero está el futuro de dolores de espalda, artritis y otras realidades de la vejez. En la naturaleza esto significa simplemente ir muriendo. Pero en el mundo de la cultura, hemos creado un mundo en el que podemos envejecer significativa $y$ plenamente. $Y$ el siguiente problema es que en la naturaleza simplemente hay otras personas.

Recuerdo que una vez se me acercó un estudiante que vivía en un carro. Me dijo que estaba en contra de la privacidad, que siempre quería estar entre la gente. En ese momento le sonreí, lo miré y le dije: "quieres el infierno". Para amar a los seres humanos necesitamos algo de tiempo lejos el uno del otro. Pero, una cosa complicada es que siempre tenemos a los seres humanos en torno a nosotros, en un mundo simbólico de la cultura que hemos creado.

Entonces, les ofrezco ahora una versión corta de cómo la cultura está relacionada con la transdisciplinariedad.Nosotros hablamos todo el tiempo sobre la cultura, pero en efecto a lo que realmente nos estamos refiriendo es a las costumbres. Las costumbres son parte de las culturas, pero la cultura es más radical.La cultura es el mundo de los significados. Esa es la dimensión en la que viven los seres humanos.Se trata de un mundo humano. Y esto significa que la cultura es siempre llegar más allá de sí misma: así como los seres humanos están llegando más allá de sí mismos, como las disciplinas van más allá de las propias disciplinas, y, de la misma manera, como ya argumenté, como el pensamiento vivo, las ideas vivas, van más allá de sí mismas. 